\title{
SOCIAL INTERACTIONS OF BLACK-BACKED JACKALS CANIS MESOMELAS IN THE KALAHARI GEMSBOK NATIONAL PARK
}

\author{
J. W. H. FERGUSON \\ S.A. Lombard Nature Reserve \\ P.O. Box 174 \\ Bloemhof \\ 2660
}

Abstract - Social interactions among black-backed jackals are recognised as amicable, agonistic and aggressive. Allogrooming within a jackal pair is common, and a fixed "greeting" ceremony takes place between the pair members. Agonistic postures are well-developed, and closely follow the typical canine pattern, with minor characteristics specific to blackbacked jackals. A behaviour pattern which is apparently rare in canines, is described - the submissive animal rests its forelegs on the rump of the dominant. Body-slamming is common. Occasionally submissive animals hide in order to avoid interactions with dominant ones. Submission is not stercotvped, but is graded into a number of steps. It would appear that the intensity of submissive postures is at least in part determined by the degree of dominance of the superior anima!. Black-backed jackals have a well-developed social life.

\section{Introduction}

Although much attention has been paid to the diet of the blackbacked jackal Canis mesomelas (Grafton 1965; Bothma 1971; Bothma, Steyn \& Du Toit 1976; Rowe-Rowe 1976; Stuart 1976), almost nothing is known of the behaviour of this animal. The problem is similar when viewing the published data on the behaviour of the coyote Camis latrans. Both these canids are extremely timid within stock-farming areas and cannot readily be observed in most free-ranging situations. This paper describes the social behaviour of black-backed jackals observed in the Kalahari Gemsbok National Park (KGNP), Republic of South Africa.

\section{Methods}

Two periods of five weeks each (November-December 1974 and July-August 1975) were spent in the Kwang area $18 \mathrm{~km}$ north of the Nossob Camp. Jackals were observed with the aid of $7 \times 50$ binoculars and two $55 \mathrm{w}$ broad-beam fog lamps fitted to the vehicle, for following 
the animals at night. The animals were generally followed at a distance of 20 to 60 metres during the night. Individuals that appeared disturbed by the vehicle and lights, were ignored. In a few cases the lamps assisted food-finding by jackals, but this would be unlikely to influence social behaviour. This paper reports on approximately 190 observation-hours on jackals, during which 116 social interactions were recorded.

\section{Categories of Social Behaviour in Canids}

Social order among canids has been well-documented (Schenkel 1967; Fox 1971; Kleiman 1967). The animals can be divided into those that have a high social status, and those that have a low social status. For brevity they can be called confident and subordinate canids, respectively. Social interactions among jackals can be divided into three categories:

(a) Aggressive interactions, in which the confident animal physically attacks the subordinate jackal, and the apparent aim of the confident animal is to harm its subordinate counterpart physically.

(b) Agonistic interactions, in which the confident animal asserts its superior social status over the subordinate jackal. Actions are mostly ritualized or exagerated. Although physical contact may occur as in aggressive interactions, it is not with the apparent intention of inflicting any bodily harm to the subordinate.

(c) Amicable interactions, in which confident or subordinate jackals cannot be clearly recognised, and no clear elements of aggression or agonism can be seen.

The first two abovementioned classes of interactions are characterised by distinct elements of threat and submission, and amicable interactions by the lack of these elements. During aggressive interactions, threat and submission are intense, and a fight/flight type of interaction is the result. During agonistic encounters, there are no signs of attack or flight by either of the interacting jackals, although threat and submission still characterize these interactions. Functionally, amicable interactions are seen as actions that strengthen social ties, i.e. the equality of social status among animals, whereas agonistic and aggressive interactions reinforce the difference in social status among animals (Fox 1971), and thus in effect seperate them socially.

Results

\section{(a) Amicable interactions}

In 23 out of 28 social interactions between pair members in which food was not involved, the behaviour of both animals towards each other was classed as friendly. There are, however, no set patterns during these friendly interactions. One member of the pair groomed the other between and behind the ears, the side of the neck, the back, the forelegs and in the anal area. Grooming around the anal area was not associated 
with any pre-copulatory behaviour, e.g. T-sequences or mounting (Golani \& Mendelsohn 1971), and allogrooming was accompanied by much selfgrooming by both animals. Allogrooming involving more than two animals were not observed. No clear elements of agonistic behaviour occurred during allogrooming. During allogrooming, the ears and tails of both animals were normal (fig. A). Occasionally their ears flattened slightly and their tails wagged slowly, in a consumatory way. Both members of a pair performed an equal amount of allogrooming. When the members of a pair had been separated for a while and met again, a short "greeting" ceremony took place. In this action, which seldomly lasted more than five seconds, the animals stood face to face with their noses touching. Their ears were usually slightly flattened, and the tail of one or both animals wagged slightly. Ritualized jaw wrestling occurred twice in one specific jackal pair. Although the one animal was momentarily dominant over the other, the situation was reversed the next moment. This was accompanied by mutual chasing. Both instances occurred during November, that is roughly six months before mating takes places (Ferguson in litt.).

On a number of occasions both members of a pair took part in the catching of springhare Pedetes capensis. The relationship between the two jackals whilst feeding was fluid. In seven out of fifteen recorded foodorientated social interactions within a jackal pair, the animals fed on the same springhare without any obvious signs of conflict. There was also no sign of one jackal being dominant over its mate. However, among nonpair members, only three of 26 interactions at a food source were amicable.

In a specific pair, two observations were made of one member keeping other jackals at bay, leaving its mate to feed on the carcass. In both incidents, both animals had participated in the capture of the springhare. In the first incident the female chased away the intruders, and in the second incident it was her mate that chased away the intruders.

The above interactions within a jackal pair are considered to be actions that reinforce the formation of an amicable association with its mate by a pair member, and thus strengthen the pair bond.

\section{(b) Agonistic interactions}

Agonistic postures and signals are well-developed in the black-backed jackal. Of the 116 observed social interactions $44(38 \%)$ belonged to this type.

(1) Dominant agonistic actions

During dominant actions the position of the tail can be anywhere between normal unaroused (Fig. A) and straight in line with the spine of the animal. On one occasion the animal held its tail in the shape of an inverted $\mathrm{U}$, when a submissive jackal approached while it was feeding (Fig. 1). During social interactions where physical contact was not involved, the tail of the dominant animal was usually elevated. In interactions where physical contact was involved, e.g. body 


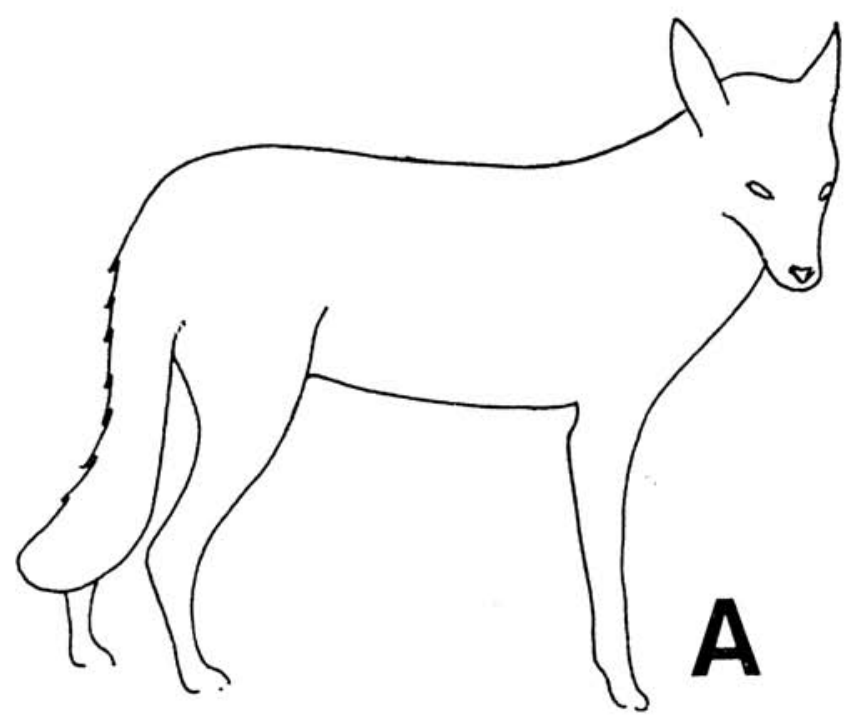

Figs. A-H The gradation of submissive postures in black-backed jackals in increasing order of submission. Unaroused posture (A), flattening of ears (B), rounding of back and depression of tail (C), submissive "grin" (D), avoidance of eye contact (E), paw raising $(\mathrm{F})$, social mounting $(\mathrm{G})$ and lateral recumbency (passive submission) (H).

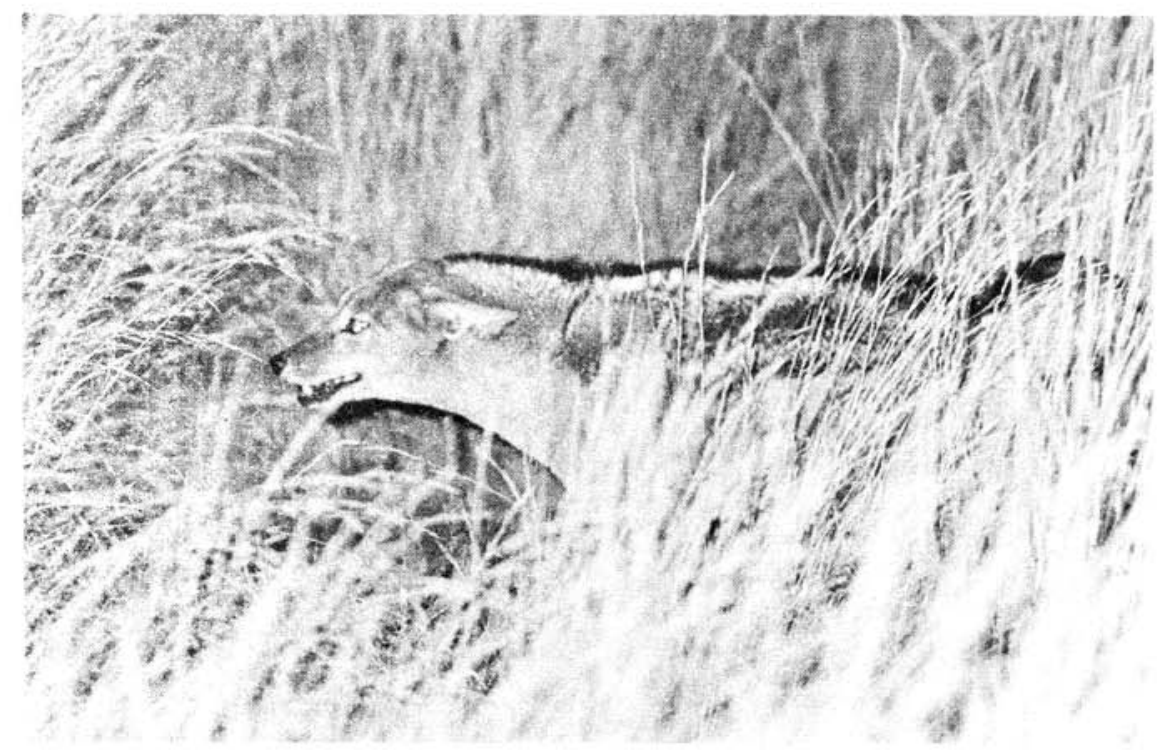

Fig. 1. Some social interactions among black-backed jackals, showing postures of one or both animals: (1) Dominant posture during a food-orientated encounter. Note the threat face, direct stare, pilo-erection and elevated tail. 

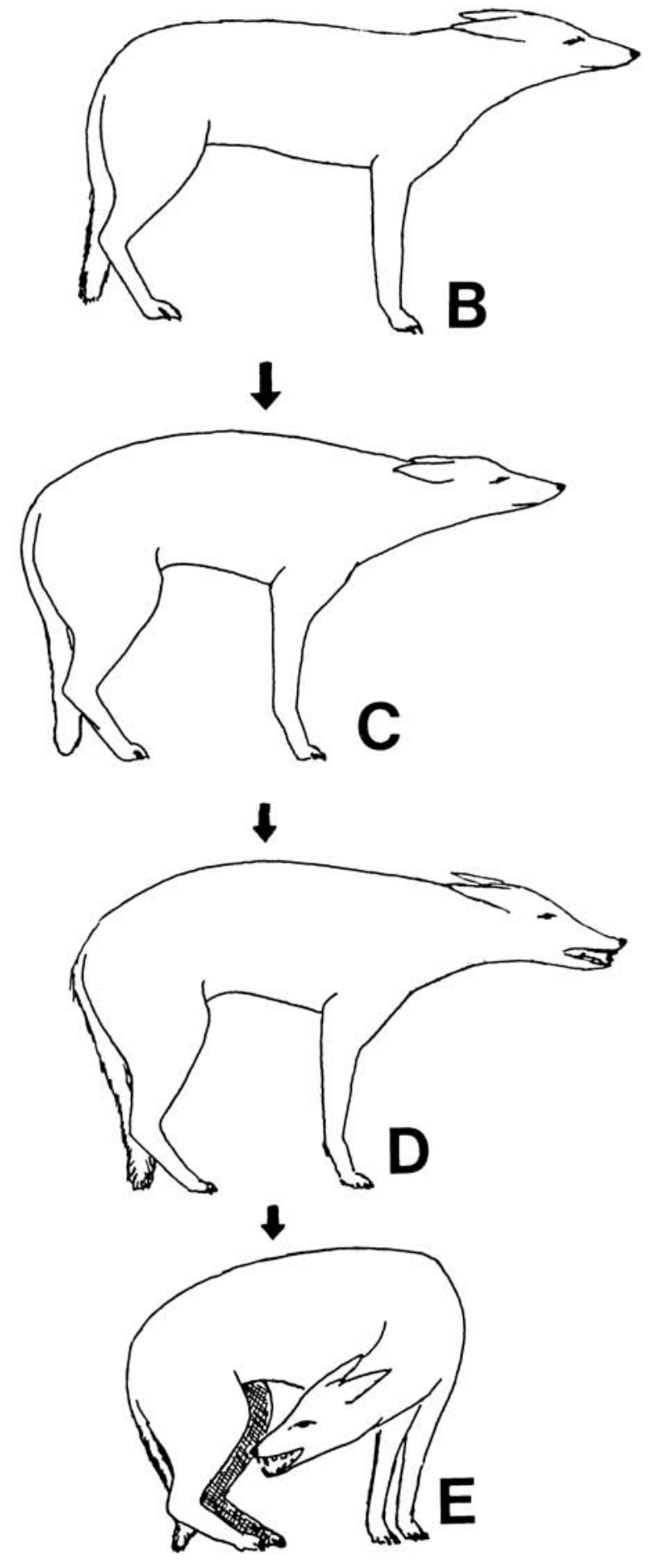


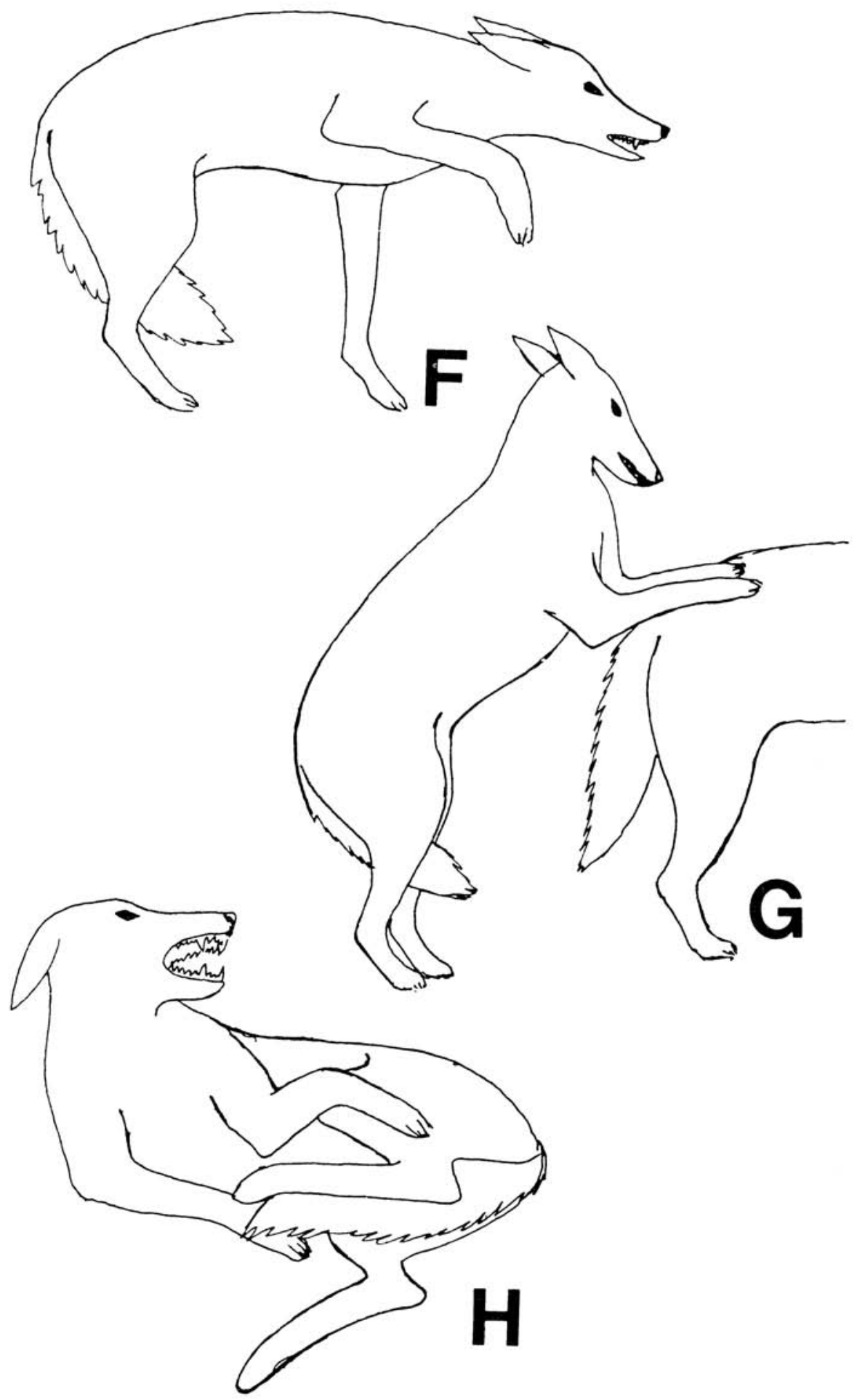


slamming, the tail was usually held in the normal unaroused way, but wagged slowly. In many instances pilo-erection on the back and tail occurred. The dominant jackal seldomly held its ears in an upright and forward manner, but usually upright and pointing backwards and outwards, so that the concave faces of the pinnae faced the ground. In dominant black-backed jackals the head was slightly lowered, and the animal stared at the submissive individual. During displays of severe dominance, the mouth was opened so that a bared-teeth grin showed while the animal vocalized.

In one case a dominant male stared at a submissive individual, which was approximately $50 \mathrm{~m}$ away, scratched the ground with its forefeet alternately then urinated on the spot. This display lasted at least four minutes. It occurred after the dominant animal had had an agonistic interaction with the submissive individual involving physical contact. Scratching the ground and urination followed alternately, but not necessarily in immediate succession.

The extreme form of signalling dominance to a submissive animal would appear to be body-slamming. In so doing the dominant animal hits the submissive animal on the forelegs and torso with its hindquarters (Fig. 2). This is an extremely rapid sequence, too fast even to be captured in any detail on cine film. What could be seen, was that during the sequence the dominant animal swings its hindquarters through an arc of at least $120^{\circ}$, and immediately afterwards returns to its original position. Body-slamming was also observed in ten week old black-backed jackal pups at a den.

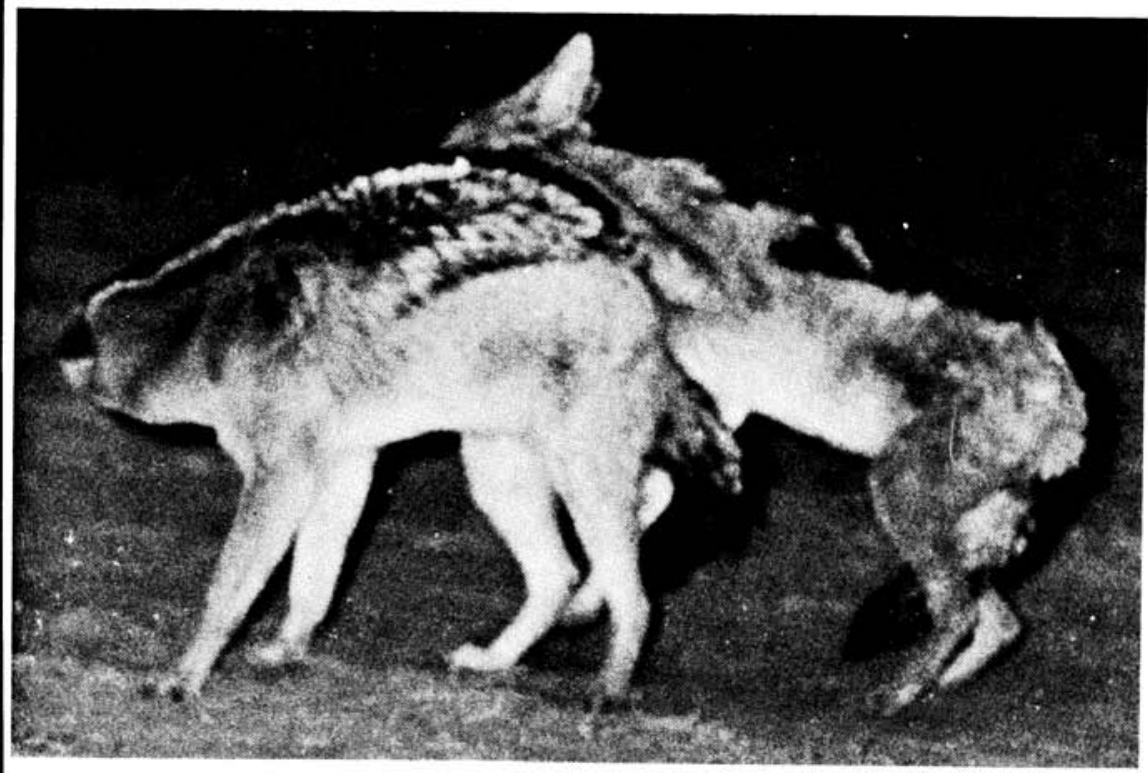

Fig. 2. Side-slamming. The submissive animal is the hindmost and the dominant animal has no raised hindfoot (see text). 
(2) Submissive agonistic actions

There is no fixed pattern of submission as such, but a gradation of postures, ranging from minor submissive actions to lateral recumbency, the most intense form of submission that was observed (figs B-H). More intense forms of submission were usually associated with more severe forms of dominance in the other animal.

Upon seeing a dominant animal, a submissive jackal retracted its ears and pressed its tail tight against its hind legs. On becoming more submissive, the head was lowered and the mouth opened in a submissive "grin" (Fig. 3). In this posture, the tail may be tucked between the legs against the abdomen. The body is rounded so that the animal assumes a semi-crouching position. According to field observations, more-submissive postures can be divided into two groups:

The animal, still with a submissive "grin", breaks eye contact with the dominant jackal and looks around. This posture was always associated with a half-crouching action.

The animal may raise one of its front paws. This action is probably derived from the "paw massage" action (Milchtritt) of puppies that are suckling (Seitz 1959). This posture was frequently associated with bodyslamming by the dominant jackal. It occasionally became even more extreme when the submissive animal put both its front paws on the rump of the dominant animal. In at least one case, pilo-erection on the back of the submissive animal took place. (Fig. G). In all the cases where the submissive animal rested both its front paws on the rump of the dominant, the sequence was preceded by sustained paw-raising by the submissive jackal.

The most extreme form of submission was lateral recumbency. This was observed only on three occasions. The subordinate broke eye contact with the dominant while lying in this position, the tail still tucked between the hindlegs.

One curious phenomenon that was observed twice during this study was the sudden dropping to the ground of a jackal in an apparent attempt to hide from another. The animals that did this had been submissive in all previous social interactions and in one case the confident jackal was known to be a dominant animal. In both instances the supposed submissive animal hid before the dominant jackal saw it. This is interpreted as an attempt to avoid social contact with dominant animals.

When the less-intense forms of submission occurrred, it often resulted in a T-sequence where the submissive animal approached the neck of the dominant animal and appeared to smell or nibble the scruff of the dominant. During this sequence, the dominant animal appeared to just tolerate the submissive jackal.

\section{(c) Aggressive interactions}

During these interactions there was a definite dominant animal and an extremely submissive jackal, but the dominant animal either physically attacked the intruder, or otherwise tried to attack an intruder if one 
came near. In all the cases observed, the submissive jackal showed a very strong flight reaction and made a hasty retreat. The flight reaction of the submissive jackal seemed to override any submissive postures. Aggressive interactions mostly occurred around food (12 or 14 observations), and was only observed once between pair members.

Another type of interaction also occurred while jackals were at food sources, e.g. a springhare carcass. One jackal would seize the carcass and try to run away with it. The other jackal would also grab the carcass, and a tug-of-war would ensue between the two animals. The carcass often changed ownership in this way. During these interactions elements of agonism occurred, e.g. a threat "grin", with retracted lips. However, neither animal was obviously submissive towards the other, and after one jackal had obtained ownership of the carcass, it was often chased by the other animal.

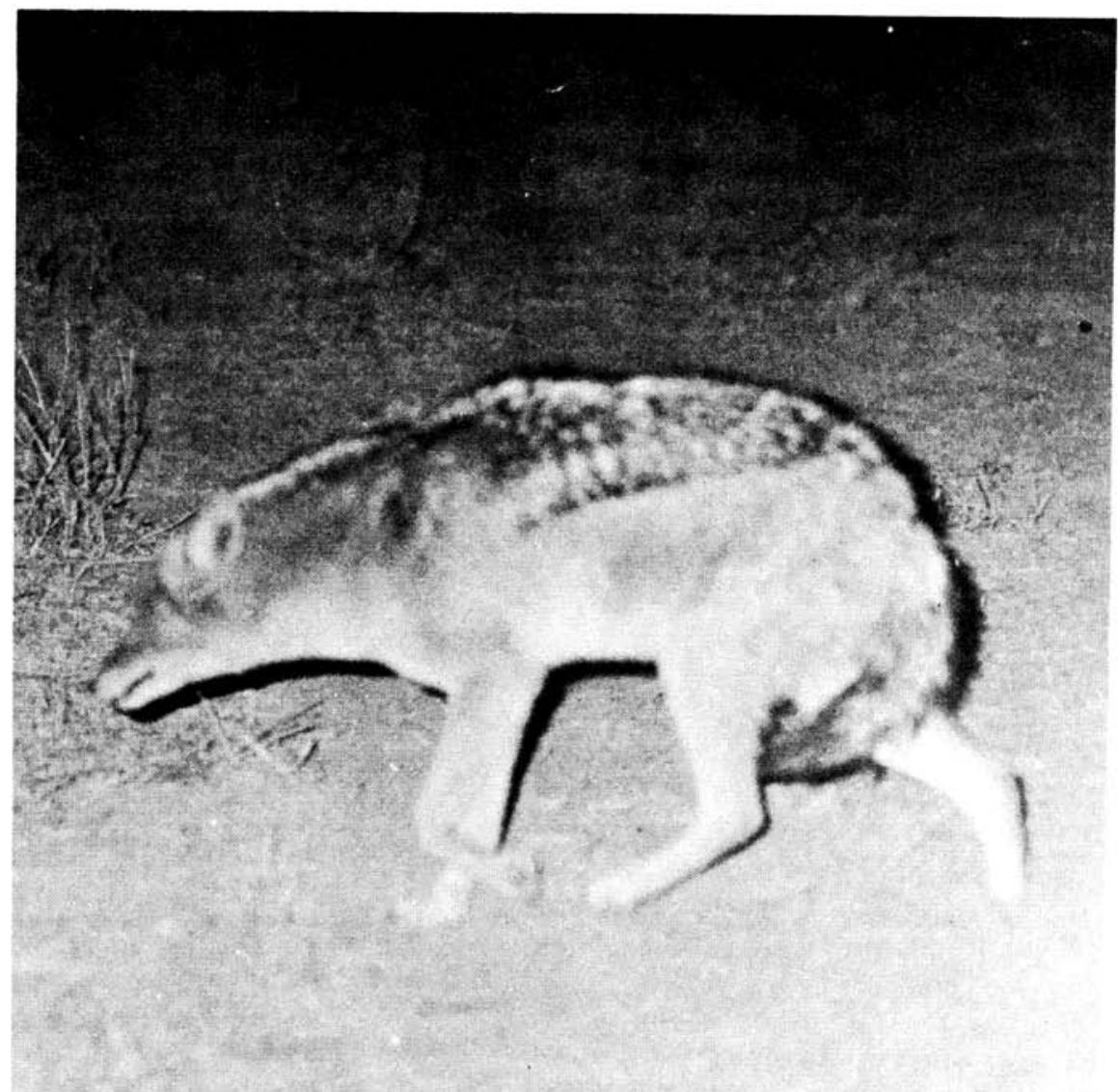

Fig. 3. Submissive posture during a purely social encounter. Note the submissive "grin", flattened ears, rounded back and tucked-in-tail. 


\section{Discussion}

There is a big difference between the occurrences of social interaction forms within a jackal pair (Table 1), and between non-pair members (i.e. among submissive, lone wanderers or between one member of a pair and a submissive singleton). Interactions within a pair are predominantly friendly, whereas they are otherwise mainly agonistic. Because the social interactions that occurred at food sources may differ from purely socially-motivated interactions, they have been separated in Table 1.

Table 1

The occurrence of social interactions between black-backed jackals in various situations in the Kalahari Gemsbok National Park

A. Interactions in a purely social context

1. Friendly

2. No reaction

3. Agonistic:

No body-slamming

Body-slamming

Lateral recumbency

4. Aggressive

5. Subordinate hides

Total

B. Interactions associated with food

1. Friendly

2. One animal takes food from the other

3. Agonistic:

No body-slamming

Body-slamming

4. Aggressive

Total

\begin{tabular}{|c|c|c|c|}
\hline $\begin{array}{c}\text { Within a } \\
\text { pair }\end{array}$ & Uncertain & $\begin{array}{c}\text { Not within } \\
\text { a pair }\end{array}$ & Total \\
\hline 23 & 3 & - & 26 \\
2 & 2 & 4 & 8 \\
2 & 2 & 33 & 37 \\
2 & 1 & 19 & 22 \\
- & 1 & 11 & 12 \\
- & - & 3 & 3 \\
1 & - & 1 & 2 \\
- & - & 2 & 2 \\
\hline
\end{tabular}

Jackals are much more aggressive towards each other when food is available. In these situations, the interactions between pair members were also much more friendly than between other jackals. This suggests that the pair bond in the black-backed jackal is strong. The conclusion that jackals are sociable animals is supported by observations on communal howling and co-operative hunting.

The behaviour patterns of black-backed jackals during social interactions show no major departures from the typical canine sequences. In submissive animals the general pattern is the lowering of the profile and 
rounding of the back (Kleiman 1967). In dominant animals the profile is raised by tail elevation, pilo-erection and the face in a threat expression (Fox 1971).

However, the social behaviour of jackals differ in a few respects from that of other canids. Compared to the posture of the ears of dominant domestic dogs and coyotes (Fox 1971), black-backed jackals appear to differ markedly. Dominant jackals seldomly held their ears in an upright and forward way, as in the above mentioned species, but in a much flatter way (Fig. 1). Kleiman (1967) noted this position in some dominant canids, although she did not mention the species in which it was observed. The tail position of the dominant jackal was never observed to assume the typical J-shape of the dominant domestic dog (Kiley-Worthington 1975).

Mounting, as observed in an agonistic context, had nothing to do with courtship as none of the accompanying acts of courtship (Fox 1971; Golani \& Mendelssohn 1971) were observed, and the dominant animals had other regular mates. This form of submission was obviously not accompanied by body-slamming from the dominant animal. However, Seitz (1959) noticed similar actions as an apparent displacement activity in captive Canis aureus. Grooming in the anal area is an important activity that immediately precedes copulation in $C$. aureus (Golani \& Mendelssohn 1971). However, the anal grooming that was observed during the present study, although taking place during July, i.e. roughly during the mating season, was never followed by copulation or any overt mating behaviour. This suggests that grooming of the anal area is not necessarily a final act before copulation in $C$. mesomelas. Similarly, the mutual chasing in black-backed jackals that was observed during November, has no clear precopulatory role as observed in C. aureus by Golani \& Mendelssohn (op. cit.).

Body-slamming was always performed by the dominant jackal using its hindquarters and not only its one hindleg and paw, as observed by Schenkel (1967), who mentions that the object of a body slam is to throw the submissive animal off balance into lateral recumbency.

There has been a certain amount of argument on the mechanism of agonistic interactions. Fox (1971), Schenkel (1967) and Kiley-Worthington (1975) indicate that aggression of the submissive animal is inhibited by this animal being fearsome of the dominant, and it is not the aggression of the dominant canid that is inhibited by the submissive displays of the subordinate. This view is supported by the fact that intense submission is usually accompanied by severe dominance in the blackbacked jackal. Although no conclusive data exists, this suggests that it is the subordinate that reacts towards the dominant animal.

When compared to the theory that solitary canids have highly stereotyped signalling behaviour patterns (Fox 1971; Kleiman \& Eisenberg 1973), the black-backed jackal, as a semi-solitary species, shows a remarkable range of visual signals and social postures. In this respect it resembles Canis aureus and Canis latrans (Kleiman \& Eisenberg 1973). 


\section{Acknowledgements}

The National Parks Board of Trustees is thanked for their cooperation. The help of District Ranger E. A. N. le Riche is greatly appreciated. Proff. J. A. J. Nel and A. Alexander as well as Mr. D. T. RoweRowe are thanked for critically going through the manuscript, and $\mathrm{Mr}$. P. Richardson for helpful comments. The Director of Nature Conservation of the Transvaal Provincial Administration is thanked for permission to publish this paper.

\section{REFERENCES}

BOTHMA, J. DU P. 1971. Food of Canis mesomelas in South Africa. Zool. afr. 6:195-203.

BOTHMA, J. DU P., A. G. W. STEYN and S. H. C. DU TOIT. 1976. Determining sample size in feeding habits studies using the blackbacked jackal in the Western Transvaal. S. Afr. J. wildl. Res. $6(2): 129-132$.

FOX, M. W. 1971. Behaviour of wolves, dogs and related canids. London: Jonathan Cape.

GOLANI, I. and H. MENDELSSOHN. 1971. Sequences of precopulatory behaviour of the jackal (Canis aureus L.). Behaviour 38:169-192.

GRAFTON, R. N. 1965. Food of the black-backed jackal: A preliminary report. Zool. afr. 1:41-53.

KILEY-WORTHINGTON, M. 1976. The tail movements of ungulates, canids and felids with a particular reference to their causation and function as displays. Behaviour 56:69-115.

KLEIMAN, D. G. 1967. Some aspects of social behaviour in the Canidae. Amer. Zool. 7:365-372.

KLEIMAN, G. G. and J. F. EISENBERG. 1973. Comparisons of canid and felid social systems from an evolutionary perspective. Anim. Behav. 21(4):637-659.

ROWE-ROWE, D. T. 1976. Food of the black-backed jackal in nature conservation and farming areas in Natal. E. Afr. Wildl. J. 14:345348.

SCHENKEL, R. 1967. Submission: its features and functions in the wolf and dog. Amer. Zool. 7:319-330.

SEITZ, A. 1959. Beobachtungen an handaufgezogenen Goldschakalen (Canis aureus algirensis Wagner 1843). Z. Tierpsychol. 16:747-771.

STUART, C. T. 1976. Diet of the black-backed jackal Canis mesomelas in the Central Namib Desert, S.W.A. Zool. afr. 11(1):193-205. 